\title{
GENDER DIFFERENCES IN COMPUTER-MEDIATED COMMUNICATION: A CASE STUDY ON MALAYSIAN MILLENNIALS
} Kirstie Tet-Mei Fung $^{1}$, Kee-Man Chuah ${ }^{2 *}$, Su-Hie Ting ${ }^{3}$

${ }^{1}$ Postgraduate Student, Faculty of Language and Communication, Universiti Malaysia Sarawak, Malaysia; ${ }^{2 *}$ Lecturer, Faculty of Language and Communication, Universiti Malaysia Sarawak, Malaysia; ${ }^{3}$ Associate Professor, Faculty of

Language and Communication, Universiti Malaysia Sarawak, Malaysia.

Email: ${ }^{1}$ exousia258@gmail.com, ${ }^{2 *}$ kmchuah@unimas.my, ${ }^{3}$ shting@unimas.my

\section{Article History: Received on $28^{\text {th }}$ December 2019, Revised on $08^{\text {th }}$ April 2020, Published on $22^{\text {nd }}$ May 2020}

\begin{abstract}
Purpose of the study: This study aims to analyse which gender language features are used by both genders in computermediated communication (CMC) and also investigates if online gender communication reflects normal face-to-face communication.

Methodology: A qualitative research design was employed in addressing the objectives of the study. A total of 260 Facebook comments were collected and analysed using more than one methodological approach in accordance with CMDA (Computer-Mediated Discourse Analysis).

Main Findings: The findings show that male language features occurred more frequently compared to female language features. However, commenters of both genders do not always follow their respective gender language features. This shows that commenters from both genders do not necessarily follow their own gender stereotypes according to the different contextual situations they face.
\end{abstract}

Applications of this study: The findings from this study can contribute to gender language studies and also benefit those who are interested in millennial research and the usage of CMC in recent times.

Novelty/Originality of this study: In this research, common framework in analysing gender differences is improved to fit the needs of current CMC trends.

Keywords: Gender Differences, Computer-mediated Communication, Millennials, Gendered Communication, Social Media.

\section{INTRODUCTION}

Language has played an integral life in shaping our thoughts and realities, which plays a fundamental core in defining us as intelligent forms of life. When a community of people are gathered, various aspects can be studied upon. From the perspective of language, it is through the discipline of sociolinguistics in which the connection between language and society is studied upon (Holmes \& Meyerhoff, 2008). Although as a community, humans usually speak in an arbitrary and shared language, by looking through the lens of sociolinguistics, we can see that there are other aspects that separate us, such as age, social class, education level and even gender.

Gender language in sociolinguistics did not seem to bring such an interest at first, as most regarded the male way of speaking in the past as a standard norm. It was not until Lakoff's (1975) work that claims that women's language was powerless compared to their male counterparts. This particular work has since then sparked interest and discussion regarding gender language. Although most of society has now acknowledged gender equality to some extent in recent years, the mode of communicating with each other has now changed in modern times and is not what it once was before.

In the present time, the norms of socializing have shifted dramatically from face-to-face conversations in person, to screen interactions with computer monitors and phones. The mode of communication that takes place in the digital world is more commonly known as Computer-Mediated Communication (CMC). December (1997) defined CMC as a process where humans are involved in engaging in particular contexts through computer communication and aims to form media for a number of reasons. The internet was supposedly regarded as a medium to achieve a neutral ground of communication in which a person's racial background or age did not matter due to the lack of visualising them (Herring, 1996; Haferkamp et al., 2012). Unfortunately, the internet has proven to be a failure in doing so, as close scrutiny showed that the linguistic aspects of discourse were still visible online (Drakett et al., 2018). With the rapid growth of $\mathrm{CMC}$ through the use of social media, this raises the question if users would use this opportunity to disguise themselves as someone else by changing their stylistic discourse. Since textual-based CMC allows users more space to express themselves (Chuah, 2013; Fletcher \& Nielsen, 2018), anything could be possible. With enough knowledge about gender language and the way it works for different contexts, it is definitely not an impossible task as those who have committed cyber identity fraud have succeeded in their ways.

Due to the internet being a social communicating platform with a great sense of animosity, it can come as an advantage and a disadvantage for every internet user. This also raises the question if gender communication styles still persist in an anonymous medium and if it masks the identity of someone's gender completely while communicating online. The study done by Herring and Stoeger (2014) indicated the fundamentals of a person's style of discourse that they themselves may 
not be conscious about, especially when these behaviours are considered as a norm. It is, therefore, crucial to further investigate gender communication styles.

In Malaysian contexts, studies regarding online gender communication patterns, especially among millennials on social media, are still in its early stages and this study may potentially add on to the understanding and contribute to the findings of past studies that have been done among Malaysians. Additionally, this study can contribute to gender language studies and also benefit those who are interested in millennial research and the usage of CMC in recent times. Thus, this paper reports on how Malaysian millennials of both genders communicate online. In particular, it aims to analyse which gender language features are used by both genders and also investigates if online gender communication reflects normal face-to-face communication.

\section{LITERATURE REVIEW}

\section{Online and Offline Gender Language}

Traditionally, men's language was considered to be the norm of communicating whereas female language was something to be explored as it differed from the standard at the time. Only after publishing prominent literature, such as Lakoff's work (1975), was gender and language studied in a different light. Since then, many studies have diverged itself from the stigma of acknowledging male language as a norm. This is where sociolinguists play a crucial role to provide new insight into the subject (Coates, 2018). It has been proven that females have the tendency to use more polite and expressive words while also giving much attention to conversations, whereas males would lean towards a more authoritative role in conversation (Basow \& Rubenfield, 2003). Aside from that, men and women have different roles in interacting with others. For instance, men tend to associate their topics on information and task, whereas women aim to strengthen their bonds and build connections with others (Morris, 2013).

Besides that, females are shown to apologize and use hedges both online and offline (Bonvillian, 2000; Walker, 2008). The assertive and directive language was found to be commonly associated in male communication styles, which appears as a dominant style of online discourse (Basow \& Rubenfield, 2003; Guiller \& Durndell, 2007; Savicki, 1996). According to Basow and Rubenfield (2003), women use more expressive, tentative and polite languages compared to men, whereas men are prone to advise on problems, but do not encourage unnecessary development of the interpersonal relationship. In fact, it has been noted that males talk more explicitly about sexual references when communicating online (Subrahmanyan et al., 2006).

On the platform of Twitter, Ott (2016) did a corpus study of gendered language and have found significant differences in terms of word usage and topics discussed. Words such as "home" and "family" were prone to be used by females who often updated their profiles with daily activities and familial life. Males, on the other hand, tweeted more about topics regarding the news, technology, sex and even anger issues. An overview of this study shows that men tend to type in longer sentences and contained more words belonging to auxiliary verb classes and articles.

\section{Computer-Mediated Communication}

CMC happens in any medium of digital communication such as instant messaging (IM), e-mails, blog posts, social media websites, etc. In reality, CMC is not as different from the texts we encounter in real life. Use of language in texts in different aspects such as legal affairs, journalistic, advertisements and so on are all found on the Internet, just as they are in their non-electronic mediums. The impressions given by messages of all departments in digital communication is as powerful as those that appear in real life, proving the kind of medium that messages appear isn't relevant in affecting the objective of persuading or informing the public (Crystal, 2001). Rather, it is the texts and the observation of language used for the sake of interaction is the main aspect that attracts the attention of the research of linguists (Locher, 2010). In linguistics itself, CMC is categorized under the applied study of sociolinguistics as it provides fresh, academic data for sociolinguists to study and analyse linguistics variability amongst social identities on the Internet (Androutsopoulos, 2014). Language is the crucial point to CMC as it focuses on how language is creatively applied and innovatively exploited at a rapid pace of linguistic change to meet the challenges of technology (Locher, 2010; Hwang, 2014). Although CMC lacks facial expression and visual cues that normally occur in normal face-to-face communication, it still manages to gratify users in getting their messages accommodated well (Dino \& Gustilo, 2015).

\section{Malaysian Millennials}

Millennials are the term referring to the group of people who were born from the 1980s until the start of the new millennium (Pew Research Centre, 2010; Gibson \& Sodemon, 2014). According to the Department of Statistics Malaysia (2016), Millennials make up nearly half of the citizens in Malaysia, with an estimation of 11 million Malaysians born in this generation. Not just only Malaysia, according to Miller and Lu (2018), Generation Y comprises of 1.8 billion out of 7 billion people globally, making them the largest generation alive in the present day. Besides that, millennials are known to be very dependent on their usage of technology (Hwa, Lee \& Cheng, 2011) due to the fact that they have grown together with the emergence of technology since the 1980s. Therefore, millennials had a huge advantage when they entered careers which required their employees to be tech-savvy. On the other hand, they fall short when it comes to face-to-face communication and neglect the importance of nurturing soft skills for their future careers (Gibson \& Sodeman, 2014). To millennials, social media does more than reading the news and connecting with each 
other. On the contrary, millennials are highly likely to utilize social media as a tool to help them in making decisions for almost anything relying on crowdsourcing and feedback from other people (Fromm, 2016). This factor certainly changes the traditional way of advertising companies work and how millennials make up their minds about something. It is also interesting to note how this demographic group has a distinctive way of communicating, which may be reflected in CMC platforms particularly in the context of social media such as Facebook.

\section{METHODOLOGY}

This study implements a qualitative research design in addressing the research objectives. This is done through a content analysis of the communication texts produced by the target sample. The social media platform is known as Facebook and its publicly accessible pages will be used to gather data. This is because public posts can be read by anyone with an account, regardless of whether a commenter has 'friended' your account or not. Moreover, Facebook's comment function is also known to have no word restrictions, therefore collection data with the continuous flow will benefit the coherence of the study.

\section{Sample and Sampling Method}

A total of 260 comments were collected from various public pages where millennials of both genders would likely comment on. This criterion for posts was set to ensure that the topics discussed would not be biased towards anyone gender in particular. As for the comments, the following requirements had to be fulfilled to be eligible to be considered data:

1. Nationality of commenters must be Malaysian.

2. Commenters had to be within the millennial age gap (born from the year 1980 to 1999) as visibly shown in their profile.

3. Comments must be written in Malay or English (both languages can be generally understood by Malaysians).

\section{Data Collection and Analysis Procedures}

In order to study computer-mediated language, Herring came up with an approach called Computer-Mediated Discourse Analysis (CMDA) which is used to study online linguistic behaviour. CMDA is supplemented by a variety of different methods in order to study and interpret what has been analysed. Furthermore, CMDA can be implemented to study micro-level linguistic phenomena (sentence structure and spelling) and also ones on macro-level (identity and social behaviour) through the lens of language (Herring, 2004).

In accordance with CMDA, samples had to be picked selectively as the context may be lost if random sampling was implemented. Based on the findings of several past studies, a framework was constructed in order to aid the researcher in identifying the linguistic markers and gender language features to their respective gender counterparts. After comments from 10 Facebook public posts from different pages were collected and the data was further analysed using CMDA alongside the said framework as shown in Table 1:

Table 1: The framework of Gender Language Styles

\begin{tabular}{|c|c|c|c|c|c|}
\hline \multicolumn{2}{|c|}{ MALE } & \multirow[b]{2}{*}{$\begin{array}{l}\text { REFERENCES } \\
\text { Jackson, Ervin, Gardner, } \\
\text { \& Schmitt }(2001) \\
\text { Bond }(2009) \\
\text { Cameron }(2010) \\
\text { Morris }(2013) \\
\end{array}$} & \multicolumn{2}{|c|}{ FEMALE } & \multirow[b]{2}{*}{$\begin{array}{l}\text { REFERENCES } \\
\text { Guiller \& Durndell } \\
\text { (2007) } \\
\text { Guadagno et al. (2011) } \\
\underline{\text { Morris (2013) }}\end{array}$} \\
\hline M1 & $\begin{array}{l}\text { Information } \\
\text { Oriented }\end{array}$ & & F1 & $\begin{array}{l}\text { Interpersonally } \\
\text { Oriented/ } \\
\text { Supportiveness }\end{array}$ & \\
\hline M2 & Self-Promotion & $\begin{array}{l}\text { Thomson, Marachver \& } \\
\text { Green (2001) } \\
\text { Herring (2003) }\end{array}$ & $\mathrm{F} 2$ & Hedges & $\begin{array}{l}\text { Herring (1996) } \\
\text { Bonvillian (2000) } \\
\text { Walker }(2008) \\
\end{array}$ \\
\hline M3 & $\begin{array}{l}\text { Sexual } \\
\text { References }\end{array}$ & $\begin{array}{l}\text { Subrahmanyam, Smahel, } \\
\underline{\text { \& Greenfield }(2006)}\end{array}$ & F3 & Apologize & $\begin{array}{l}\text { Herring (2003) } \\
\text { Walker (2008) }\end{array}$ \\
\hline M4 & $\begin{array}{l}\text { Insults/ } \\
\text { Profanities } \\
\text { (Word choice) }\end{array}$ & $\begin{array}{l}\text { Herring (1996) } \\
\text { Thomson, Marachver \& } \\
\text { Green }(2001)\end{array}$ & $\mathrm{F} 4$ & $\begin{array}{l}\text { Polite and } \\
\text { emotionally } \\
\text { expressive words } \\
\text { (word choice) }\end{array}$ & $\begin{array}{lll}\text { Basow \& Rubenfield } \\
\underline{(2003)}\end{array}$ \\
\hline M5 & $\begin{array}{l}\text { Directive/ } \\
\text { Autonomous }\end{array}$ & Postmes \& Spears (2002) & F5 & $\begin{array}{l}\text { Questions (to an } \\
\text { illicit response) }\end{array}$ & $\underline{\text { Cameron (2010) }}$ \\
\hline M6 & $\begin{array}{l}\text { Rhetorical } \\
\text { Questions }\end{array}$ & Herring (1996) & F6 & Tag Questions & Cameron (2010) \\
\hline
\end{tabular}




\begin{tabular}{llllll}
\hline M7 & $\begin{array}{l}\text { Opposed } \\
\text { Orientation }\end{array}$ & $\frac{\text { Coates (1993) }}{\text { Herring (2003) }}$ & F7 & Aligned Orientation & $\frac{\underline{\text { Coates (1993) }}}{\text { Herring (2003) }}$ \\
& & & & $\frac{\underline{\text { Guiller \& Durndell }}}{\text { Guiller \& }}$ \\
& $\underline{\text { Durndell (2007) }}$ & $\underline{\text { Herring (1996) }}$ & F8 & $\begin{array}{l}\text { Attenuation/Sharing } \\
\text { Experience }\end{array}$ & $\frac{\underline{\text { Herring (1996) }}}{\text { Guiller \& Durndell }}$ \\
\hline M8 & $\begin{array}{l}\text { Strong } \\
\text { Assertions }\end{array}$ & & (2007) \\
\hline
\end{tabular}

After analysing comments, they were further put into the following 4 categories with accordance to the gender language features from the framework:

1. Male Styles: Comments that consist of significant male gender language features.

2. Female Styles: Comments that consist of notable significant female gender language features.

3. Combined Styles: Comments that consist of gender language features from both genders.

4. Neutral Styles: Comments that do not consist of gender language features from both genders.

If the information of a commenter's gender is visually displayed in their profile, it will be taken into consideration as to ease the researcher in identifying the commenter's gender without ambiguity. In terms of content, Facebook posts will be extracted verbatim without being judged during the selection process. The public accessibility of extracting comments from public pages allowed the researcher to copy and paste the comments into word documents to be analysed afterwards. Such an example of a Facebook comment is shown below:

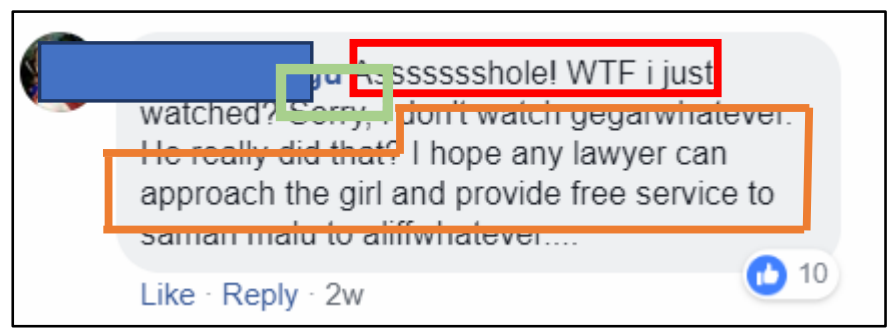

Figure 1: Sample of Comment with Combined Gender Language Features

The above comment shows traces of more than one gender feature. Just by observation alone, it can be seen that the red boxes highlighting profanities. On the contrary, the commenter also apologizes (as shown by the green box). The commenter also expresses hope for the person of the said subject to seek legal action from a lawyer (from the orange box). This, therefore, hints an interpersonal oriented goal to be the concern of their goodwill. We can conclude that this comment has a male gender feature (M4-profanity) as well as a female one (F3 -apologizing and F1-interpersonally oriented/supportiveness). Thus, summarizing that this comment is categorized under 'combined styles' for having gender language features of both male and female. Comments such as graphic images are also taken into consideration as long as the amount of texts in the image is notably sufficient to represent an opinion or a response. This is because texts are still shown; therefore, comments such as these were valid to be taken as data.

\section{RESULTS}

In order to achieve this study's objectives, this includes analysing the type of gender language features used by Malaysian millennials on Facebook. From a total of 260 comments found in 10 Facebook posts were assigned under four different categories, namely male style, female style, mixed and neutral. Table 2 shows the number of comments when grouped according to the said categories. It is rather apparent that the male language style dominates the communication via the Facebook platform, regardless of the actual gender of the person engaging in the discussions.

Table 2: Number of Comments Grouped According to Respective Categories

\begin{tabular}{ll}
\hline Category & Total \\
\hline Male Language Style & 161 \\
\hline Female Language Style & 57 \\
\hline Combined Language Style & 34 \\
\hline Neutral Language Style & 8 \\
\hline Total Comments & 260 \\
\hline
\end{tabular}

Based on Table 3, it is evident that most of the data comprise of comments that are dominantly written with male language features. Profanities and insults posts as the most frequent features found in all 260 comments, whereas self- 
Table 3: Occurrences of Gender Language Features Found in Comments

\begin{tabular}{llllll}
\hline Male & Occurrences & Female & Occurrences \\
\hline M1 & Information-Oriented & 14 & F1 & Interpersonally-Oriented/ Supportiveness & 23 \\
\hline M2 & Self-Promotion & 3 & F2 & Hedges & 4 \\
\hline M3 & Sexual References & 7 & F3 & Apologize & 6 \\
\hline M4 & $\begin{array}{l}\text { Insults/ } \\
\text { Profanities (Word Choice) }\end{array}$ & 81 & F4 & $\begin{array}{l}\text { Polite and Emotionally Expressive Words } \\
\text { (Word Choice) }\end{array}$ & 13 \\
\hline M5 & Directive/Autonomous & 60 & F5 & Questions (To Illicit Response) & 15 \\
\hline M6 & Rhetorical Questions & 26 & F6 & Tag Questions & 4 \\
\hline M7 & Opposed Orientation & 5 & F7 & Aligned Orientation & 14 \\
\hline M8 & Strong Assertions & 39 & F8 & Attenuation/Sharing Experience & 27 \\
\hline
\end{tabular}

promotion is recorded as the least occurred among all the gender language features of the framework. One of the factors could be due to female commenters who are not afraid to use M4 (profanities and other degrading terms).

Figure 2 shows an example of a male language featured comment. It shows a rhetoric question (M6) as shown in the green box and an insult (M4) in the orange box.

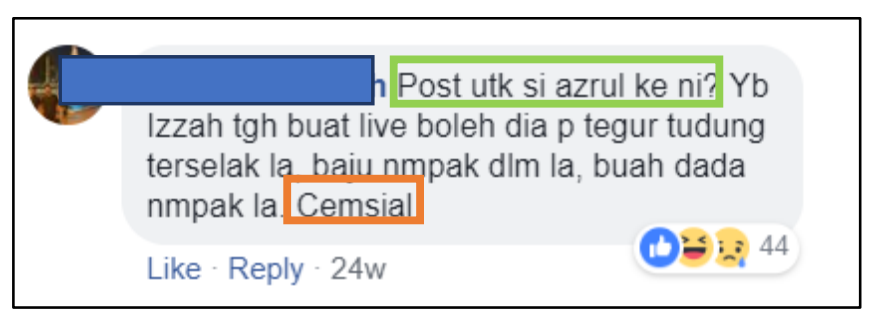

Figure 2: Comment with Male Language Features Written by a Female Commenter

Some comments retain a mixture of both male and female language features, such as comments shown below. In figure 3 , the commenter writes a profane word (M4) but also agrees with the OP, thus showing aligned orientation (F7).

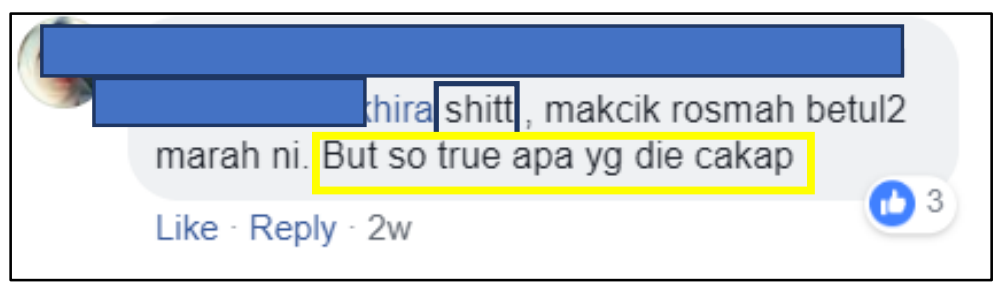

Figure 3: Comment with Male Language Features Written by a Female Commenter

However, there were instances when male commenters would use female language features in their comments too. Nonetheless, all gender language features were still found in the 260 comments chosen as data. As shown in figure 4 , the male commenter is not afraid to share his personal experience and advises the readers. Although it is clear that the topic discussed is more of a male-oriented issue (smoking), however, the commenter talks about his past and urges other people to be considerate of others when smoking. Aside from that, the advice said was typed in a polite manner instead of being demanding, a prominent male language feature.

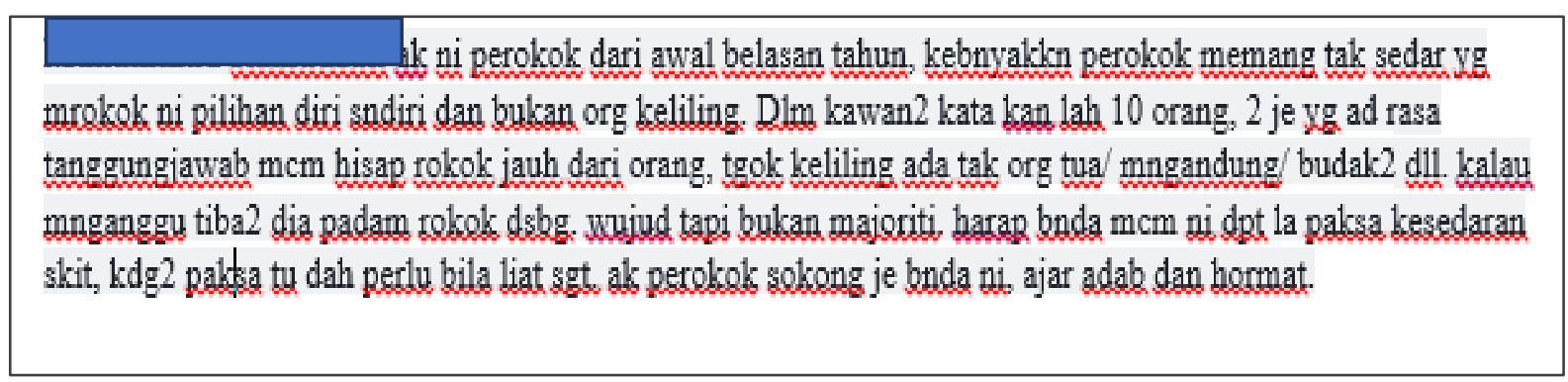

Figure 4: Comment with Combined Language Styles

Regardless, some comments did not have any of the gender language styles mentioned. Therefore, they were placed under the neutral category. For instance, figure 5 shows a comment made with sarcasm because the commenter asks his reader not to forget 'Winston' (a cigarette brand) in a post talking about the smoking ban in restaurants. 


\section{Brother winston jgn lupa}

Figure 5: Comment with Neutral Language Styles

\section{DISCUSSION AND CONCLUSION}

The objectives of the present study are to analyse the gender language features found in CMC among Malaysian millennials as well as investigate if these gender language features reflect normal face to face communication features. This study implements CMDA methodologies to study linguistic behaviour as portrayed in the CMC of Malaysian millennials. The results of this study prove that Malaysian millennials often take on male language features when interacting. However, this does not infer that female language features are not used at all (as similarity found in Cameron, 2010). Rather, it has heavily relied on the context of a post in which different language features are used, however, it is also based on how commenters wish to react through these said posts through their textual discourse.

Nonetheless, there are some instances when the process of analysing the comments gender language features and assigning them into its respective categories is not as clear cut as it seems. In traditional face to face communication, the goal for interaction differs between male and female (being information and interpersonally oriented respectively). To an extent, this fact still stands within the online community; however, it is proven that males are able to be interpersonally oriented when the context of a discussion requires them to be sympathetic as found in previous studies such as Thomson et al. (2001). This shows that they do not feel embarrassed faced with a situation which requires them to feel sorry with or towards others. Although the occurrences for information-oriented features is lower than that of interpersonally oriented trait, it was discovered that males were still often shown to be factual in their discourse, staying true to their nature of providing knowledge and facts whenever an opportunity presents itself.

Hedges are a form of meta-discourse and are used to express uncertainty or soften a speaker's utterances (Holmes, 2001). Hedges found in comments were sometimes a bit hard to distinguish when it came to Malay comments, as the examples used in past literature were mostly in English. Nonetheless, some examples of English hedging have been found and do not seem to occur very often in CMC among Malaysian Millennials. In oppose to hedging found in previous studies by Herring (2004) and Holmes (2001), strong assertions are more likely associated with a male's way of speaking when they are certain of what they are referring to. Although both genders do retain their respective way of speaking, there are instances when the lines are crossed or even blurred. A mixture of both types of gender language is not a rare occurrence and happens almost as natural as the opportunity that presents itself to the commenter (Herring, 2003). In other words, it is no longer consider taboo or strange when a female commenter is spotted spouting profanities in their comments or when a male commenter shares their personal experience to anyone reading their comments, sometimes in an attempt to give personal advice.

When comparing these finding to actual face-to-face language cues, it should be understood that in times of modernisation, traditional language cues have already started to shy away from the norms of how women must be polite (Gibson \& Sodeman, 2014), and men must speak with authority ever since Western gender equality movements have begun spreading. Especially in Malaysia, politeness is known to be a cultural norm practiced by almost all of its ethnic groups. However, since Malaysians still practice these cultural traits out of habit or courtesy on a daily basis, therefore it is safe to say it might be a rare occurrence to see a Malaysian behave out of the character of politeness. Insults, for example, are rare although commonly used as a form of the Internet language rather than truly trying to insult a person as found in the study by Thomson et al. (2001). Most of these insults found in this study were more of self-expressions of emotions.

Through the sampling of data, it was found that some profiles used to comment on posts were secondary accounts. These accounts were used to protect commenters from others who wished to find more information to bash or stalk their identities. Though not an uncommon thing to do, it should be noted that Facebook has privacy settings that can be adjusted so that personal information can be withheld from onlookers. However, this may not be a safe measure for those using these secondary accounts, as they may want to distance themselves from the persona they portray themselves as via the comments they type. While this act may act as a countermeasure to prevent others from digging deeper into who they are, it comes back to the root of the problem that this research aims to focus on, that is, anyone being able to disguise themselves as someone else just by the way they talk.

This may infer that while Malaysians do their part in fulfilling their cultural roles as members of their own ethnic races by behaving in the norms they were taught. On the contrary, their online personas may be something of a real version of what they wish to convey about something. This, however, calls for more of a psychological and ethnological angle of study. As for a linguistic perspective, while it can be easy to detect linguistic features of both male and female online, this can pose a harder problem to identify whether the person conversing is really who they say they are when we do not know them. While it can act as an advantage for linguists assisting crime investigations about identity fraud online, it also becomes an upper hand for those who are committing the same crime. 


\section{LIMITATIONS AND FUTURE STUDIES}

The findings from this study have shown that more studies are needed to address the issue of gender differences in online communication. In particular, it shows the gap in understanding how male and female users hide their identities through the use of different communicative strategies which marked a specific gender. It is pivotal to address this as it may lead to a greater concern of identity and privacy in the cyber world. The sample in this study is also limited to Malaysian millennials, which may not be reflecting the real situation in a more global sense.

\section{ACKNOWLEDGEMENT}

We would like to thank Universiti Malaysia Sarawak for the support in this study as well as participants who have given their consent to use their postings for academic research purposes.

\section{AUTHORS CONTRIBUTION}

The first author has contributed in terms of formulating the framework for this research and in carrying out the data collection and analysis process. The second author provided the necessary review for the research and assisted in the data analysis while the third author contributed in the discussion and synthesis of the findings.

\section{REFERENCES}

1. Androutsopoulos, J. (2014). Computer-mediated Communication and Linguistic Landscapes. In Holmes, J. \& Hazen, K. (Eds.), Research methods in sociolinguistics: a practical guide (pp. 74-90). Malden: Wiley Blackwell.

2. Basow, S. A., \& Rubenfield, K. (2003). Troubles talk: Effects of gender and gender-typing. Sex Roles, 48(34), 183-187. https://doi.org/10.1023/A:1022411623948

3. Bonvillian, N. (2000). Language, culture and communication. New Jersey: Prentice Hall Inc.

4. Bond, B. J. (2009). He posted, she posted: gender differences in self-disclosure on social network sites. Rocky Mountain Communication Review, 6(2).

5. Cameron, R. (2010). Growing up and apart: Gender divergences in a Chicagoland elementary school. Language Variation and Change, 22(2), 279-319. https://doi.org/10.1017/S0954394510000074

6. Chuah, K. M. (2013). Aplikasi media sosial dalam pembelajaran Bahasa Inggeris: Persepsi pelajar universiti. Issues in Language Studies, 2(1), 56-63. https://doi.org/10.33736/ils.1680.2013

7. Coates, J. (1993).Women, men and language ( $2^{\text {nd }}$ ed.). London: Longman.

8. Coates, J. (2018). The rise and fall (and rise) of Mars and Venus in language and gender research. New York: Routledge. https://doi.org/10.4324/9781315619644-1

9. Crystal, D. (2001). Language and the Internet. Cambridge, UK: Cambridge University Press. https://doi.org/10.1017/CBO9781139164771

10. December, J. (1997). Notes on defining of computer-mediated communication. Computer Mediated Communication Magazine, 3(1). Retrieved from http://www.december.com/cmc/mag/1997/jan/december.html

11. Department of Statistics Malaysia. (2016). Population of Malaysia. Retrieved from http://www.statistics.gov.my

12. Dino, C., \& Gustilo, L. (2015). Digitalk: An exploration of the linguistic features of CMC. International Journal of Languages, Literature, and Linguistics, 1(1), 51-55. https://doi.org/10.7763/IJLLL.2015.V1.11

13. Drakett, J., Rickett, B., Day, K., \& Milnes, K. (2018). Old jokes, new media-Online sexism and constructions

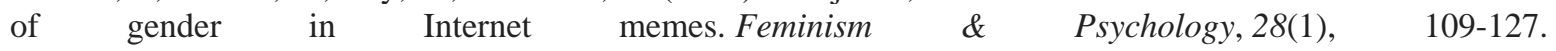
https://doi.org/10.1177/0959353517727560

14. Fletcher, R., \& Nielsen, R. K. (2018). Are people incidentally exposed to news on social media? A comparative analysis. New Media \& Society, 20(7), 2450-2468. https://doi.org/10.1177/1461444817724170

15. Fromm, J. (2016, May). What you need to know about millennial travellers. Retrieved from http://www.millennialmarketing.com/2016/05/what-you-need-to-know-about-millennial-travelers/

16. Gibson, L. A., \& Sodeman, W. A. (2014). Millennials and technology: Addressing the communication gap in education and practice. Organization Development Journal, 32(4), 63-75.

17. Guiller, J., \& Durndell, A. (2007). Students' linguistic behaviour in online discussion groups: Does gender matter? Computers in Human Behavior, 23(5), 2240-2255. https://doi.org/10.1016/j.chb.2006.03.004

18. Guadagno, R. E., Muscanell, N. L., Okdie, B. M., Burk, N. M., \& Ward, T. B. (2011). Even in virtual environments women shop and men build: A social role perspective on Second Life. Computers in Human Behavior, 27(1), 304-308. https://doi.org/10.1016/j.chb.2010.08.008

19. Haferkamp, N., Eimler, S. C., Papadakis, A., \& Kruck, J. V. (2012). Men are from mars, women are from venus? Examining gender differences in self-presentation on social networking sites. Cyber Psychology, Behavior \& Social Networking, 15(2), 91-98. https://doi.org/10.1089/cyber.2011.0151

20. Herring, S. C. (1996). Two variants of an electronic message schema. In Herring, S. C. (Ed.), Computermediated communication: Linguistic, social and cross-cultural perspectives (pp. 81-108). New York: John Benjamins. https://doi.org/10.1075/pbns.39.08her 
21. Herring, S. C. (2003). Gender and power in on-line communication. In Holmes, J. \& Meyerhoff, M. (Eds.), The handbook of language and gender (pp. 202-228). Hoboken, NJ: John Wiley \& Sons. https://doi.org/10.1002/9780470756942.ch9

22. Herring, S. C. (2004). Computer-mediated discourse analysis: An approach to researching online behavior. In. Barab, S. A, Kling, R., \& Gray, J. H. (Eds.), Designing for virtual communities in the service of learning. New York: Cambridge University Press. https://doi.org/10.1017/CBO9780511805080.016

23. Herring, S. C., \& Stoerger, S. (2014). 29 Gender and (A)nonymity in Computer-Mediated Communication. In Holmes, J.\& Meyerhoff, M. (Eds.), The handbook of language and gender (pp. 567-586). Hoboken, NJ: John Wiley \& Sons. https://doi.org/10.1002/9781118584248.ch29

24. Holmes, J. (2001). An Introduction to sociolinguistics. England: Pearson Education.

25. Holmes, J., \& Meyerhoff, M. (Eds.). (2008). The handbook of language and gender (Vol. 25). Hoboken, NJ: John Wiley \& Sons.

26. Hwang, H. S. (2014). Gender differences in emoticon use on mobile text messaging: evidence from a Korean sample. International Journal of Journalism \& Mass Communication, 1, 1-4. https://doi.org/10.15344/23492635/2014/107

27. Hwa, E. T. B., Lee, E. L. W., \& Cheng, R. (2011). Generation y and choice of mobile service provider: A study on their purchasing decisions in choosing a mobile service provider. In 2nd International Conference on Business and Economic Research Proceeding.

28. Jackson, L. A., Ervin, K. S., Gardner, P. D., \& Schmitt, N. (2001). Gender and the Internet: Women communicating and men searching. Sex Roles, 44(5-6), 363-379. https://doi.org/10.1023/A:1010937901821

29. Lakoff, G. (1975). Hedges: A study in meaning criteria and the logic of fuzzy concepts. In Contemporary Research in philosophical logic and linguistic semantics (pp. 221-271). Springer, Dordrecht. https://doi.org/10.1007/978-94-010-1756-5_9

30. Locher, M. A. (2010) Introduction: politeness and impoliteness in computer mediated communication. Journal of Politeness Research, 6. 1-5. https://doi.org/10.1515/jplr.2010.001

31. Miller, L. J., \& Lu, W. (2018, August 20). Gen Z is set to outnumber millennials within a year. Retrieved from: https://www.bloomberg.com/news/articles/2018-08-20/gen-z-to-outnumber-millennials-within-a-yeardemographic-trends

32. Morris, E. (2013). She likes it, He doesn't: Gender differences in Facebook communication Behaviors. Unpublished undergraduate thesis, University of Colorado at Boulder.

33. Ott, M. (2016). Tweet like a girl: A corpus analysis of gendered language in social media. Unpublished Doctoral dissertation, Yale University.

34. Pew Research Centre (2010, February 24) Millennials. Confident. Connected. Open to change. Retrieved from http://www.pewsocialtrends.org/2010/02/24/millennials-confident-connected-open-to-change/

35. Postmes, T., \& Spears, R. (2002). Behavior online: Does anonymous computer communication reduce gender inequality? Personality and Social Psychology Bulletin, 28(8), 1073-1083. https://doi.org/10.1177/01461672022811006

36. Savicki, V. (1996) Gender language style and group composition in Internet discussion groups. Journal of Computer-Mediated Communication, 2(3). https://doi.org/10.1111/j.1083-6101.1996.tb00191.x

37. Subrahmanyam, K., Smahel, D., \& Greenfield, P. (2006). Connecting developmental constructions to the Internet: Identity presentation and sexual exploration in online teen chat rooms. Developmental Psychology, 42(3), 395. https://doi.org/10.1037/0012-1649.42.3.395

38. Thomson, R., Murachver, T., \& Green, J. (2001). Where is the gender in gendered language? Psychological Science, 12, 171 - 175. https://doi.org/10.1111/1467-9280.00329

39. Walker, K.L. (2008). Women's Communication and Language. In Wolfgang, D. (Ed.), The international encyclopaedia of communication. NY: Blackwell. https://doi.org/10.1002/9781405186407.wbiecw007 